\title{
Critical Linkages: Poverty, Livelihoods, Institutions, and Community Development in Poverty Reduction
}

\author{
Dinka Tesema $\mathrm{W} /$ mariyam (PhD candidate) \\ Department of Governance \& Development Studies, Wollega University, Nakamte, Ethiopia
}

\begin{abstract}
Currently, sustainable livelihood approach has been getting attention than conventional approach for poverty minimization for the reason that conventional approach considered as narrow focused. The sustainable livelihood approach is framed in complex manner subsumed different dimensions and elements where poverty, livelihoods, institutions, and community are the critical. Thus, this papers aims to examine the critical linkages among between poverty, livelihoods, institutions, and community development in context of sustainable livelihoods framework. To address the objective of study, descriptive research design and qualitative research approach applied. The study demonstrates that poverty, livelihoods, institutions, and community development are influencing one another, but institutions either formal or informal are vital because they influences directly or indirectly access to livelihood resources, community development, livelihood strategy, and, in due course, the scope for sustainable livelihood outcomes.
\end{abstract}

Keywords: Poverty; livelihood; institutions; community development; sustainable livelihood approach

DOI: $10.7176 / \mathrm{PPAR} / 10-6-02$

Publication date:June 30th 2020

\section{Introduction}

Nowadays, the concepts of Sustainable Livelihood (SL) approaches have been getting more attention than conventional approaches for poverty reduction. Conventional approaches had been relied on certain aspects of poverty such as low income, health sector, or agriculture sector. Thus, the benefits of livelihoods thinking and approaches are widely have been getting recognition for the reason that it stresses the various factors and processes that either disenable or enable poor people in owning claim and access of assets using their capabilities of living in an economically, ecologically, and socially sustainable manner. Thereby, in comparison with so far approaches, SL offers the prospects of a more coherent and integrated approach for poverty reduction (Krantz, L., 2001, p. 1, $5)$.

Moreover, SL brings attention to bear on the inherent potential of people in terms of their skills, social networks, and access to physical and financial resources, and ability to influence core institutions (Serrat, O., 2010, p. 4). To understand the complex and differentiated processes through which livelihoods constructed, hence, it is imperative to analyze how the poverty, livelihood, institutions, and community development interrelate and influence one another in order to identify those issues of subject areas where an intervention could be strategically important for effective poverty reduction.

To analyze the linkages between poverty, livelihood, institution, and community development, the paper adapted the British Department for International Development (DFID) sustainable livelihood framework with a little bit modification in order to situate and illustrate community development interlinks in this framework. To achieve its objective, this study begins by outlining some of the conceptual issues of the poverty, livelihood, institutions, and community development; materials and methods; results and discussions.

\section{Poverty}

1. Concepts of poverty, livelihood, Institutions, and community development

Poverty is a complex concept that has no consensus by scholars in framing its definitions, approaches, and measurements. Thereby, at individual and group, different approaches stresses on distinct aspects of poverty such as income, capabilities, and quality of life (Maxwell, S., 1999, p. 2).

In close proximity to comprehensive aspect, poverty conceptualized as interlinked forms of deprivation capability in the economic, psychological, political, socio-cultural, resources, and protective spheres (Maxwell, S., $1999 \mathrm{p} \mathrm{2-4).} \mathrm{On} \mathrm{another} \mathrm{hand,} \mathrm{poverty} \mathrm{delineated} \mathrm{as} \mathrm{it} \mathrm{is} \mathrm{sense} \mathrm{of} \mathrm{helplessness,} \mathrm{dependence,} \mathrm{lack} \mathrm{of} \mathrm{opportunities,}$ self-confidence, and self-respect on the part of the poor. Moreover, poverty is an objectively described as well as socially and psychologically constructed lack of resources and relational power. (Narayan et al., 2000 cited in Handley, G., Higgins, K., Sharma, B., Kate Bird, K., \& Cammack, D., 2009, p. 1).

These concepts of poverty illustrates as poor people are facing a number of constraints that inhibit them to participate in fruitful and meaningful way in different aspects of life as well as policies, structures, process, and institutions. On another words, individuals, people, households, and certain groups or classes of poor and vulnerable women and men must actually are disenabling access and claims, which meant, capitals in order to turn endowments into real livelihood and 'environmental entitlements', through their knowledge, skills, and in particular the social institutions that mediate their claims. These disenabling includes in political empowerment, making 
decision, rights, voice; economic - income, livelihoods, and work; human- health, and education; socio-cultural status and dignity; and protective-insecurity, risk, and vulnerability (Bastiaensen, J., De Herdt, T., \& Vaessen, J., 2002, p .3).

In this usage, poverty is related of a certain groups, community's or society's socio-cultural well being, tangible and intangible resources/assets, as well as institutional and political orders. In this view, poverty related to the nature of social networks and the poor people's place in these networks that extended to lack of a sense of belonging, identity, agency, and the capacity to act. This has led to more questions on how these different kinds of networks function and how they evolve, but, it gives a direction in order to fight it, it needs being in individual, community and society context. On other hand, poverty minimization needs comprehensive approach along with different actors at all levels.

\subsection{Livelihoods}

In straightforward, livelihood is a means of gaining a living in which capabilities, equity, sustainability uses as a means and end. In broad terms, livelihood comprises the capabilities, assets (including both material and social resources) and activities required for a means of living (Chambers, R. \& Conway, R.G.1991, p. 6). Accordingly, a livelihood is sustainable when it can cope with and recover from stress and shocks and maintain or enhance its capabilities and assets both now and in the future, without undermining the natural resource base.

Livelihood sustainability viewed through environmental and social. Environmental sustainability illustrates the external impact of a livelihood on other livelihoods that is its effects on local and global resources and other assets, while social sustainability concerns the internal capacity of a livelihood to withstand outside pressure that is to cope with stress and shocks and retain its ability to continue and improve over time. In this convention, pressures that has a feature of continuous and cumulative and to some extent predictable, such as seasonal shortages, rising populations or declining resources stress whereas shocks are impacts that are typically sudden, unpredictable, and traumatic, such as fires, floods and epidemics (Chambers, R. \& Conway, R.G., 1992 cited in Krantz, L., 2001, p. 6).

There are crucial concepts in livelihood such as livelihood strategy, livelihood assets, livelihood outcome, and vulnerability context. Livelihood strategy is the range and combination of activities and choices that people make in order to achieve their livelihood goals whereas livelihood assets refer to the resource base of the community and of different categories of households. The livelihood outcomes that poor individuals or households achieve with their strategies are a result of all these factors - their assets, their vulnerabilities and the policies, institutions and processes that either enhance or restrict their livelihood options. In this livelihood outcome concept, vulnerability denotes unpredictable events that can undermine livelihoods and cause households to fall into poverty (Women's Commission for Refugee Women, 2009, p.3).

There are different livelihood assets. However, these different livelihood assets subsumed under five main capitals. Namely, human capital- active labor, education, knowledge and skills; natural capital- access to land, forests, water, grazing...etc.; physical capital- livestock, equipment, vehicles, houses; financial capitalsavings/debt, gold/jewellery, income, credit, insurance; and social capital-. kin networks, group membership, socio-political voice and influence (Carloni, S.A., \& Crowely, E. 2005, p. 3).

\subsection{Institutions}

Leftwich, A. (2006) categorized institutions as formal and informal. The author describe formal institutions usual set up and make up by binding laws, regulations and legal orders, which prescribe what should be done or should not be done. Informal institutions are social fabricated based up on conventions, norms, and values and accepted ways of doing things, whether economic, political, or social; these embedded in traditional social practices and culture, which can be equally binding (p. 1).

As it is obvious, both institutional (informal and formal) arrangements have different implications particularly, institutions, which ensure strong property rights in land (or anything else for that matter) can enhance productivity despite it, encourage inequality (ibid, p. 1). Complementing of this, many literature demonstrates as institutions affect the performance of economy (North, D.C., 1990 p 3 \& Scoones 1998 cited in Krantz, L., 2001, p. 10).

Thus, the differential performance of economies over time fundamentally influenced by the way institutions evolves. In addition, Institutions influence the range of livelihood options open to different categories of people. They also influence access to assets and vulnerability to shocks in which in turn manipulate the poverty (North, D.C., 1990 p 3; Carloni, S.A. ,\& Crowely, E., 2005, p . 4).

\subsection{Community Development}

Community development is a process whereby all citizens are involved in the process of community change and improvement. Community development process is always guided by a set of values and beliefs and ethical standards. Community development viewed as both a process and an outcome (Phillips, R., \& Pittman, R.H., 2009, p. 6, 37). In the community development is a process that activity and efforts come from the local people themselves aims to collaborative effort to promote what they consider to be the well being of their community( Behzad, S., Ahmad, N., 2012, p. 1). 
The process of community development is social capital/capacity building, which leads to social capital then, in turn leads to the outcome - community development. The primary needs of a community are poverty eradication and community organization. The satisfaction of community needs and aspiration is a primary objective of sustainable community development. Social essential is for poor for the reason that it has greater effect on household welfare than investment in primary education. This helps at a time of vulnerability. They are more likely to participate in collective action and be able to draw on community resources in times of need (WB, 2000, p.34).

\section{Analytical framework for assessing linkages}

It is assumed that the framework provides the structure in showing how a investigator defines his/her study philosophically, epistemologically, methodology and in situating and contextualizing formal theories into their studies as a guide (Grant \& Osanloo, 2014; Ravitch \& Carl, 2016 cited in Adom, D., Hussein, K.E., \& Agyem, A. J., 2018, p. 438). To demonstrate the interactions of poverty, livelihood, institutions, and community development, this study preferred to use sustainable livelihood frameworks rationalizing as sustainable livelihood have holistic perspective that helps look at the connections between the micro situation and actors, institutions and processes. It illustrates how households derive their livelihoods by drawing on capabilities and assets to develop livelihood strategies composed of a range of activities (Krantz, L., 2001, p. 10).

In following sustainable livelihood framework, the study does not consider as rural or urban, rather than as a general to demonstrate interlinks of poverty, livelihood, institutions and community development since no literature separately confined framework to rural or urban only. Because of people view the world in different ways and conceptualize, theorize the relations between things differently, according to Carney, D., Drinkwater, M., Rusinow, T., Neefjes, K., Wanmali, S., \& Singh, N. (1999) there are different sustainable livelihood frameworks that have been constantly contested, adapted, and refined( P. 7-12). According to the authors, the main frameworks includes the UK Department for International Development (DFID), UN Development Programme (UNDP), Oxfam Great Britain, CARE and other agencies were some of the first agencies to focus on the connection between famine, food security and sustainable livelihoods as methods for poverty reduction.

The study adapted the UK Department for International Development (DFID) Framework with little bit modification in order to situate and illustrate the inter links of community development. DFID the sustainable livelihood approach selected because it focuses on analysis while other aforementioned are on procedure for programming or planning. Moreover, in DFID's sustainable livelihood framework, power relations are included as one aspect of 'transforming processes', closely linked to 'culture' and 'institutions', and it is a dimension of intra-community relations to be examined together with other authority patterns when undertaking social analysis of particular localities (Krantz, L., 2001, p. 4). Hence, this study invested DFID's sustainable livelihood framework as tool to illustrate how poverty, livelihood, institutions, and community development interact.

\section{Methodology and Materials}

This study is used descriptive research design along with qualitative approach. The descriptive design aims to describe how poverty, livelihoods, institutions, and community development affect among other whereas qualitative approach is to demonstrate concepts of different literature towards linkages of among between to find the problems in poverty eradications using sustainable livelihood approach. The study used secondary sources of data. Qualitative data analysis applied using narrative analysis technique.

\section{Results and discussions}

In the sustainable livelihood framework, poverty can be conceptualized as of an inadequate or unsuccessful livelihood outcome. Successful livelihood outcomes through livelihood strategies results into food security, income security, health, well-being, asset accumulation and high status in the community, in turn minimize poverty. Whereas, unsuccessful livelihood outcomes consequence into include food and income insecurity, high vulnerability to shocks, loss of assets and impoverishment that escalates the depth and intensity of poverty (Messer, N., \& Townsely, P., 2003, p. 8).

As it presented in below framework, livelihood strategies and outcomes are not merely depends on access to capital assets or constrained by the vulnerability context; they are also transformed by the environment of structures and processes. According to Krantz, L. (2001) interpretation, in DFID sustainable livelihood framework, structures are the public and private sector organizations that set and implement policy and legislation; deliver services; and purchase, trade, and perform all manner of other functions that affect livelihoods (p.19).

Policy-determining structures cannot be effective in the absence of appropriate institutions and processes through which policies can be implemented. Processes are important to every aspect of livelihoods. They provide incentives that stimulate people to make better choices. They grant or deny access to assets. Serrat, O. (2010) assets that one of the central problems the poor and vulnerable face is that the processes- absent of participation in policies, which, resulted into systematically exclusion from the benefit of policies, laws, and institutions ( p. 3).

Hence, based up on its nature, institutions have its own role in reducing or increasing poverty. Accordingly, disenabling policies, institutions, and processes restraints poor individuals (households) to access asset that in turn lead into deficient of poor individuals' livelihood options. This encourages the opportunity of fall back on in an 
emergency makes them vulnerable to shocks. In the way of that, shocks contribute to negative livelihood outcomes and further depletion of household assets, which bring in deepening poverty (Carloni, S. A. \& Crowely, E., 2005, p. 4).

Conversely, enabling policies, institutions and processes, poor households or individuals enjoy a broader livelihood asset base, which widens their livelihood options and reduces their vulnerability to shocks. This enables the poor individuals to pursue winning livelihood strategies and to achieve positive livelihood options. Because of this, it assumed that development projects enable poor households to overcome their poverty through helping poor households to build up their assets; transforming the policy and institutional context from one that disable the poor to pro-poor; and reducing vulnerability, by strengthening resilience at community and household level(ibid).

Community development is another that influences poverty. According to Phillips, R., and Pittman, R.H. (2009), livelihood much more success when it based up on community consensus - poverty reduction much more visible where there is community development. Moreover, community development assumed to poverty reduction via increasing the supply and improving the condition of basic community-level infrastructure; building capacity at community level; and increasing the supply of service-providers such as public, NGO and private (Carloni, S.A. \& Crowely, E. 2005, p .30).

These also supplemented by Osei-Kufuor, P. and Koomson, F. (2014) insisting empowering people through capacity building increases the likelihood of their participation in community activities. Increased levels of empowerment allow the community to have influence over things that matter and obtain power over decisions, enabling them to move from powerless non-participants to active and effective citizens (P. 2). Hameed, G. Abdul Saboor, A., Khan, U.A., Ali, I., Wazir, K. M. (2016) viewed community development is not only improve of life of poor, it also necessary for sustainable development (p.3).

On other hand, institutions manipulate community development in facilitating, directing, or inhibiting community development. Accordingly, it facilitates contributing in creating a sense of social cohesion, improving interpersonal relations and developing an awareness of belonging to one's community; supporting and stimulating self-help, voluntary service and other types of spontaneous association; developing civic consciousness, mutual respect and dialogue between different cultures and ethnic groups in the community etc( Mayer, N., \& Keyes, L., 2005, p .19).

Conversely, disabling institutions are unable local community development via inhibiting participation in community-level socio-cultural and political activities, which are part of the livelihood system, can undermine the effectiveness of poverty reduction efforts. Community and household assets are influenced by policy and institutional context and the vulnerability context.

In this, the vulnerability context denotes to unpredictable events that can undermine livelihoods and cause households to fall into poverty. Some of these factors are pest and disease epidemics: economic shocks: civil strife: seasonal stresses: environmental stresses: idiosyncratic shocks and structural vulnerability. In this usage, shocks that originate from outside the community affect all people in the same locality whereas idiosyncratic shocks is principally affect only individual households( Carloni, S. A., \& Crowely, E. 2005, p.3).

Institutions influence household livelihood strategies directly, by determining which activities are legal/illegal and appropriate/inappropriate for women and men, by creating incentives to pursue certain activities and choices over others, and by influencing perceptions of the effectiveness of particular strategies for achieving desired outcomes. Local institutions also affect household livelihood strategies indirectly through their influence on access and control of household assets (ibid, p. 5).

The policies, structures, and processes are obviously hugely diverse and complex, and they operate at several levels, from the social group and local community to agreements between governments. They can also be influenced by people in a more or less direct way at local, national, and also international levels. Citizens' groups, as part of 'civil society' representing certain institutions and also certain social capital, are in turn also influenced by the policies and behavior of government and private businesses (Messer, N., \& Townsley, P., 2003, p. 75-80).

Politically, almost, policies and formal structures and processes are means to regulate the use of power and the dominance of one social forces (culture group) knowledge group over another. Laws and policies define rights, but power may not be exercised as easily as that. Power cannot be expressed in straightforward capitals either, whether social or human or financial capital, yet it is an essential factor in the ability to pursue one livelihood strategy or another (ibid) 
Figure 1: Sustainable livelihood framework

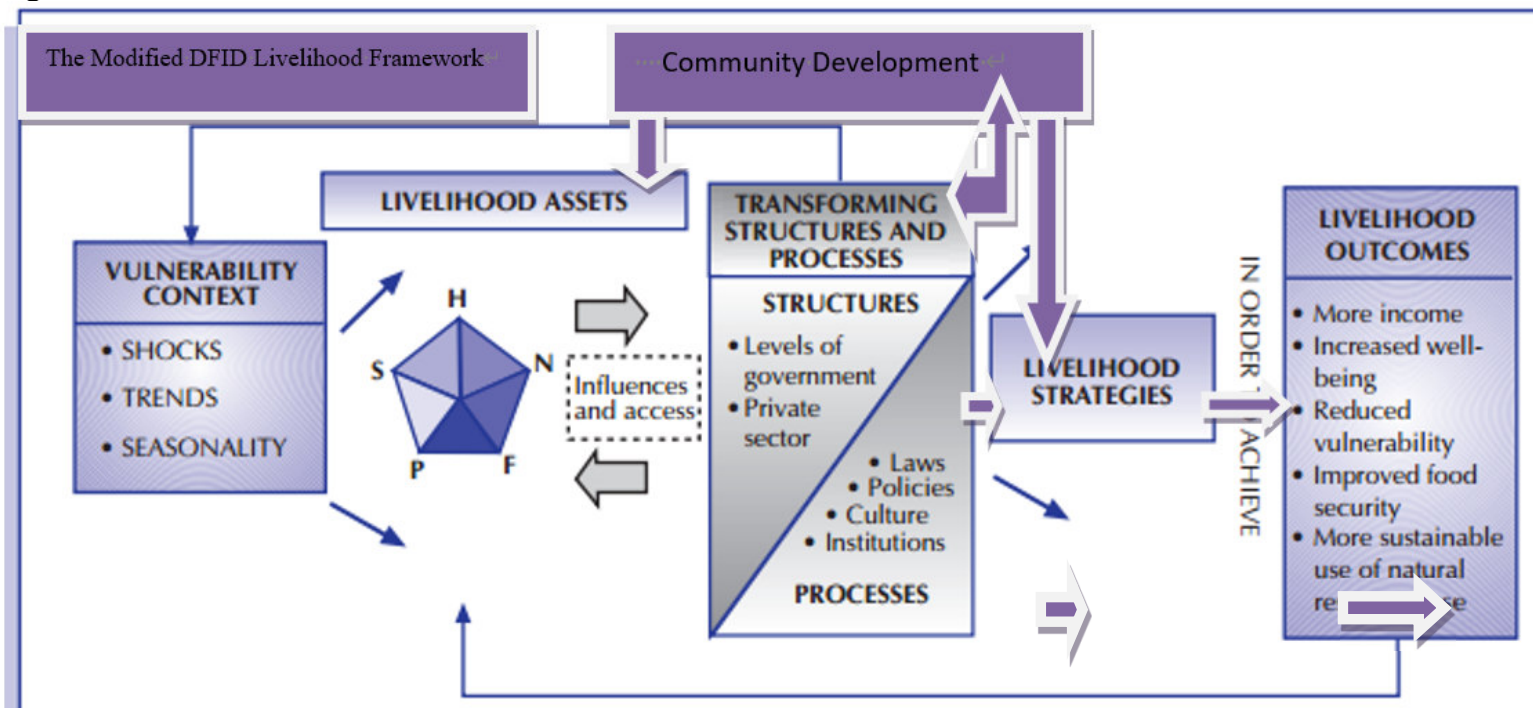

H represents human capital: the skills, knowledge, ability to labour and good health important to the ability to pursue different livelihood strategies;

P represents physical capital: the basic infrastructure (transport, shelter, water, energy and communications) and the production equipment and means that enable people to pursue livelihoods;

S represents social capital: the social resources (networks, membership of groups, relationships of trust, access to wider institutions of society) upon which people draw in pursuit of livelihoods;

F represents financial capital: the financial resources which are available to people (whether savings, supplies of credit or regular remittances or pensions) and which provide them with different livelihood options; and

$\mathrm{N}$ represents natural capital: the natural resource stocks from which resource flows useful for livelihoods are derived (e.g. land, water, wildlife, biodiversity, environmental resources).

Adapted from DFID (2000)

The figure 1 depicts that vulnerability context impacts on the livelihood assets that denoted by a pentagon. Local institutions influence household livelihood strategies and community development directly, by determining which activities is legal/illegal and appropriate/inappropriate, disabling or enabling (Carloni, S.A. \& Crowely, E. 2005, p. 3).

Local institutions also affect household livelihood strategies and livelihood outcome indirectly through their influence on access and control of household assets. On other hand, community development influences institutions more or less directly by putting pressure on exert constant pressure on agencies as they adopt policies, reframe programs, or reconsider regulations. Community development also indirectly influences livelihood outcome through directly influencing livelihood strategies and livelihood assets by capacity building and resource mobilizations (Mayer, N., \& Keyes, L., 2005).

Livelihood outcomes influence livelihood assets either the ability to preserve and accumulate household assets or asset depletion, which also directly caused by losing strategy due to directly influence of disenabling policies, institutions and processes. The feedback arrow from policies, processes, and structures to vulnerability context suggests that, whereas people cannot directly influence this context, some inroads can be made through policy change and the collective action of governments and others, in particular in respect of non-natural trends and shocks. Livelihood outcomes have a strong influence on both how capitals (i.e. assets, capabilities) are built up, and also on how they are substituted for one another, although the latter happens in particular in the process of pursuing livelihood strategies(Carloni, S.A. \& Crowely, E., 2005,p. 5).

Structures, policies, laws, markets, cultural practices, and institutions are influencing livelihood assets through defining rights and responsibilities and in defining terms on which different capitals can be used and (re)generated, and be substituted for others. They are decisive in determining whether capitals can be used by poor and marginalized people or not (Messer, N., \& Townsley, P., 2003, p. 78-80).

\section{Conclusion}

While in DFID sustainable livelihood the framework, it might be possible to identify poverty, livelihood, institution and community development dimensions and other elements of what constitutes sustainable livelihoods, it is considerably more difficult to determine what the critical factors, or constraints are in a real situation. Seeing that it is based up on the particular context that needs in that background analysis on one hand and perceptions to livelihood either to say sufficient or insufficient is subjective. 
However, institutions play great role in the sustainable development since policies, processes and institutions are thus of key importance for the creation of livelihood opportunities and strategies of poor and excluded people. Institutions indirectly influence poverty because it mediates access to livelihood resources, which in turn affect livelihood strategy options and, ultimately, the scope for sustainable livelihood outcomes. Moreover, institutions affects community development directly by determining which activities are legal/illegal and appropriate/inappropriate and influence on access and control of assets. Beyond of this, it plays in developing civic consciousness, mutual respect, and dialogue between different cultures and ethnic groups in the community.

Community development influences institutions directly exerting constant pressure on agencies as they adopt policies, reframe programs, or reconsider regulations. Community development influences livelihood outcome that process of falling into poverty or getting out of poverty indirectly via capacity building - developing the ability act, and social capacity - ability to act.

\section{Conflict of interests}

The author has not declared any conflict of interests.

\section{References}

Adom ,D., Hussein, K.E., \& Agyem, A.J. (2018). Theoretical and conceptual framework: Mandatory ingredients of a quality research. International Journal of Scientific Research 7 (1) pp 438-441.

Bastiaensen, J., De Herdt,T \& Vaessen, J. (2002). Poverty, institutions, and interventions: a framework for an institutional analysis of poverty and local anti-poverty interventions. Retrieved from https://www.researchgate.net/publication/46449521

Behzad, S., Ahmad, N. (2012). The role of the community in community's development: Promotion of self dependence through education. African Journal of Business Management, Vol. 6(49), pp. 11896-11901.

Carloni, S. A., \& Crowely, E. (2005). Rapid guide for missions: Analyzing local institutions and livelihoods. Rome: FAO

Carney, D., Drinkwater, M., Rusinow, T. Neefjes, K. Wanmali, S., \& Singh, N. (1999). Livelihoods approaches compared: A brief comparison of the livelihoods approaches of the UK Department for International Development (DFID), CARE, Oxfam and the United Nations Development Programme (UNDP). London: Department for International Development.

Chambers, R., \& Conway, R. G. (1991). Sustainable rural livelihoods; Practical concepts for the 21 st Century. Retrieved April 26, 2020 from http:/www.smallstock.info/reference/IDS/dp296.pdf

DFID. (2000). Sustainable livelihoods guidance sheets. Department for International Development.http://www.livelihoods.org/info/info guidancesheets.html (accessed: 11-5-2020.)

Handley, G., Higgins, K., Sharma, B., Bird,K., \& Cammack, D. (2009). Poverty and poverty reduction in SubSaharan Africa; An overview of key issues. Working paper no. 299, London : Overseas Development Institute.

Hodgson, M.G. (2006). What are institutions; Institutions and Pro-Poor Growth. Briefing paper no.1, doi: $10.1080 / 00213624.2006 .11506879$

Krantz, L. (2001). The sustainable livelihood approach to poverty reduction; Division for policy and socioEconomic analysis. Stockholm: Sida.

Leftwich, A. (2006). What are institutions? Research program consortium on improving Institutions and Pro-Poor Growth (IPPG). Briefing paper no. one, Manchester: University of Manchester.

Maxwell, S. (1999). The Meaning and measurement of poverty: Poverty briefing. London: Overseas Development Institute

Messer,N., \& Townsely, P. (2003). Local institutions for livelihoods: Guide lines for analysis. Rome: FAO

North, D.C. (1990). Institutions, institutional change, and economic performance. Cambridge, Cambridge University Press.

Olsson, L., M. et al. (2014). Livelihoods and poverty: Impacts, adaptation, and vulnerability. New York, USA.

Osei-Kufuor, P., \& Koomson, F. (2014). Reducing poverty through community participation: The case of the national poverty reduction program in the Dangme-West district of Ghana. International Journal of Development and Sustainability, Vol. 3 No. 8, pp 1611-1628.

Phillips, R., \& Pittman ,R..H.(eds). (2009). An introduction to community development. New Work: USA.

Serrat, O. (2010). The sustainable livelihoods approach. Washington, DC: Asian Development Bank.

Women's Commission for Refugee Women. (2009). Building livelihoods: A field manual for practitioners in humanitarian Settings. Retried from womensrefugeecommission.org.

World Bank. (2000). The local level institutions study: Local institutions, poverty and household welfare in Bolivia. Working Paper No. 9, Washington, D.C.: USA. 